\title{
Human factors and maintenance in delivery transportation: drivers' work outside the cab in focus
}

\begin{abstract}
Purpose: To investigate safety at truck drivers' work outside the cab with a special focus on work environment and equipment maintenance to prevent occupational accidents.
\end{abstract}

Design/methodology/approach: Two statistical databases on Finnish occupational accidents for truck drivers are analysed. Firstly, the national accident statistics database is examined to understand the broad context, and secondly a database on fatal accidents is analysed to better understand the root causes of the accidents and their relationship to human factors in maintenance. Based on the root cause analysis, four accident scenarios are created, and risk management measures are prioritized by occupational safety and health specialists $(n=7)$.

Findings: The study shows that there are a variety of accidents in truck drivers' work. Most of the accidents occur outside the cab while performing tasks other than driving. Further, in-depth analysis of the fatal accidents increases understanding of the possibilities of different risk management and maintenance actions in preventing such accidents.

Research limitations/implications: Databases contain different limitations concerning the data.

Practical implications: Truck drivers' work environments are wide in nature. Efficient safety management requires broad participation from different stakeholders. In addition to safe work activities, work environment and equipment maintenance is highlighted as a key component for safe and fluent delivery transportation.

Social implications: Road transportation forms a backbone of modern society. Accidents affect the efficiency of transportation and cause manifold costs reaching all the way to the societal level.

Originality/value: This study adds an important dimension of delivery transportation to a current scientific discussion on human factors and maintenance.

Keywords: Delivery transportation, human factors and ergonomics, maintenance, occupational safety, road transport, tasks outside the cab, truck driver, work environment

\section{Introduction}

Freight transport by road forms a backbone of industries' value chains and for nations' wealth and wellbeing (Douglas and Scwartz, 2017; Douglas et al., 2019). Various types of goods are transported daily by road and delivered to different customers. Despite the technological development of transportation vehicles and logistics systems, road transportation, as a labour-intensive industry, is still highly dependent on the health and well-being of its employees. Regardless of this fact, the number of accidents and mortality and morbidity rates have remained high among professional drivers all around the world (van der Beek, 2012; Apostolopoulos et al., 2014). Given this, it is evident to pay more attention to road transportation safety in academic research.

To go in-depth into road transportation safety research, it is pertinent to understand different characteristics of transportation work. Road transportation can be defined into different categories based on the transportation modes. Often, from the driver's point of view, it is practical to divide transportation into short-haul (or local) and long-haul operations. The driver, as the operator of the truck, is in the centre 
for both types of operations. In short-haul operations, drivers' tasks include a variety of other tasks besides driving; drivers make multiple stops at various locations and constantly perform manual handling of materials and load movement tasks (Cantor, 2008; Olson et al., 2009; Chandler et al., 2017). Based on various studies, drivers are considered to be flexible objects that adjust themselves in prevailing conditions, while other stakeholders, like the transportation companies and clients, make efforts to minimize their costs in the light of their own - often economic - objectives. This, in turn, complicates safety in practice (Anumba et al., 2000; Custódio and Oliveira, 2006; Cantor 2008; de Langen \& Chouly, 2009). Thus, it is easy to agree with the conclusions, for instance, that Cantor (2008) has made on the hazardous nature of truck drivers'work and challenges for safety management at logistics and value chains.

During their routine workdays, truck drivers encounter different variables, including the routes, weather, traffic conditions and different delivery locations (Douglas and Swartz, 2017). Scientific discussion concerning truck drivers' occupational safety and health (OSH) has been active for years, and authors like Friswell and Williamson (2010), Shibuya et al. (2010), Chandler et al. (2017) and Reiman et al. (2018) have shown how a majority of the occupational accidents in the transportation industry occur while performing tasks outside of the cab of the truck. Such tasks are performed constantly in a variety of different work environments where the employer faces challenges in supervising safety (Cantor, 2008; Shibuya et al., 2010). The quality and safety of these work environments varies widely (Shibuya et al., 2010) and, for instance, in the Nordic countries, the weather conditions form a specific type of challenge for such work environments and their maintenance and cleaning. Weather challenges are not only related to issues like working in snow and on icy grounds but are more complex from the OSH perspective. During their operations, the drivers are constantly required to combine outdoor work in cold winter conditions and indoor work within the cabs of trucks and at the customers' premises. This is an OSH challenge due to, for instance, thermoregulatory changes in the human body (Reiman et al., 2018).

In addition to the work environments, the technical equipment used should be acknowledged when drivers' safety is discussed. Work outside the cab is usually performed manually or with the use of a variety of different technical equipment, such as roll cages, dollies, hand trucks, lifting hooks, pallet trucks, racks and various information and communication technology-based tools. Even though these tools might have been originally designed to quicken and ease the workload, practice has shown that they are often used incorrectly or they may actually be suboptimal with respect to ergonomics and usability (Fathallah et al., 2000; McClay, 2008; Reiman et al., 2014; Bedinger et al., 2016). In such cases - as the driver usually works alone - justification for incorrect use or the decision not to use these tools at all is often based on the need to keep up with a tight schedule (Anderson et al., 2017). As can be concluded from the literature above, delivery truck drivers face various OSH challenges during their daily work. Next, we focus on the stakeholders that could contribute to improving the working conditions of truck drivers.

\section{Human factors and ergonomics in road transportation}

The focus of this study is on road transport, in particular, on work performed outside the cab by truck drivers during delivery operations. Such tasks include loading and unloading cargo, securing cargo, refuelling and tasks related to inspecting and maintaining equipment. Human factors and ergonomics (HFE) as a design-oriented framework enables in-depth discussion of such tasks, from both the aspects of productivity and safety and well-being. HFE has its roots in understanding and balancing physical and cognitive loads of work. During the last decades, this rather individual-focused and human-centric approach has been expanded to cover more in-depth different organisational aspects of work. Current understanding of HFE emphasises a sociotechnical systems approach, stakeholder interaction and networking, and the proactive role of HFE (Dul et al., 2012; Karwowski, 2012). Further, system flexibility and adaptability to changing situations is highlighted as a key contributor to efficient operations in HFE literature (Hollnagel, 2011). 
A concept of organizational ergonomics has been introduced as a framework for shifting understanding from individual-centric HFE to organisational and system-centric macroergonomics. It should be noted, however, that this shift towards increasing understanding of the organisational-level aspects does not mean that the individual-level microergonomics should not be forgotten when developing work. As Kleiner (2006) concludes, these should be implemented jointly, as macroergonomics enables larger system-level acceptance to microergonomic interventions.

The concept of a system is multifaceted. A system can be described as a work system, where the human is an employee performing a specific operational task or function within a specific environment, or a product or service system, where the human is the user of a product or the person receiving the service (Carayon and Smith, 2000; Dul et al., 2012). At its simplest, a system may constitute one individual that is using a hand tool in a certain environment, or a system can be as complex as a factory plant or a multinational organisation with actors around the world (Carayon and Smith, 2000; Dul et al., 2012). In the context of transportation, a singular driver's work system may, for instance, constitute their driving task that is performed from the cab of the truck, which is the work environment. However, in the case of delivery transportation, the cab is not the only work environment for the driver, and neither is the truck the only technological device used. Instead, delivery drivers constantly work manually or with some assistive devices and tools at various work environments, such as in their cab, cargo space, customers' premises and courtyards and other public places. Thus, a work system from a delivery driver's perspective is a far more complex entity than solely just the truck, with various other variations in the elements of their work systems. For instance, Reiman et al. (2018) have discussed this complexity and the need for flexibility and adaptability from the truck driver's perspective. Based on their study, singular truck drivers' possibilities to affect their work systems are very limited. Instead, organisational-level actions are required from top management, foremen, co-workers and route planners. In addition, interorganisational actions from other stakeholders, like the clients, possible third parties that own the clients' premises and support services that provide janitorial, cleaning and maintenance services, are required.

HFE literature has introduced theories of a balanced work system and balanced organisation (Smith and Carayon-Sainfort, 1989; Carayon and Smith, 2000). Accordingly, disorders and risks concerning an individual person's work systems should be minimized to be able to increase human well-being and productivity. Individuals whose work systems are in balance comprise a balanced organisation (Smith and CarayonSainfort, 1989). For instance, Reiman and Väyrynen (2018) and Carayon and Smith (2000) have discussed that the outcomes of a balanced organisation may be realised through improved individual and overall productivity; efficiency and quality; better loyalty by the employees; and the enhanced reputation of the organisation. Furthermore, a reduced number of accidents, incidents, health disorders, quality errors, delays and material losses can be seen as outcomes of a balanced organisation.

When a balanced organisation is discussed from the delivery transportation perspective, some pertinent issues should be acknowledged. As described, drivers' abilities to balance their own work systems are quite limited and other stakeholders' actions are needed. However, as deliveries are made at work environments that are not supervised by the transportation company, work system balance is not achieved in practice merely with intra-organisational actions. Instead, as the drivers work alone at different work environments whose maintenance and supervision practices might be blurry, it is reasonable to acknowledge other stakeholders outside the transportation company who have direct or indirect possibilities and responsibilities to balance drivers' work systems.

From the driver's perspective, their work environments may be roughly divided into five areas: home terminals, truck cabs, cargo spaces, clients' premises, and courtyards and public areas (Reiman et al., 2018). The transportation company is the main stakeholder responsible for securing and maintaining safe work environments at the first three mentioned areas (home terminals, truck cabs and cargo spaces). However, 
concerning the latter two (clients' premises and courtyards and public areas), duties to secure and maintain the work environments lay in the hands of other stakeholders. Understanding such multifaceted work environments as those associated with delivery transportation with various different stakeholders involved, it is reasonable to agree with Parida et al. (2015) who point out in their review that the relationship between the operators (understood in this study to be the drivers) and the stakeholders maintaining the work environments is a critical success factor for safe and fluent delivery operations. A better understanding of practical work environment challenges and enhanced communication between the key stakeholders should be acknowledged when delivery times, infrastructure restrictions, and other requirements and procedures are considered in supply chain and delivery logistics development (GarcíaArca et al., 2018). In this context, better possibilities for utilising mobile technologies for communicating HFE and safety should be considered, as proposed by Barata et al. (2018).

Thus, in this study, the focus is on work environments where the delivery truck drivers constantly work, but those that are not easily managed and maintained by the transportation company for which the drivers work. The aim of this study is to deepen the understanding of the challenges the drivers face and examine the stakeholders whose responsibility it is to maintain and secure such work environments. Furthermore, we aim to analyse in-depth fatal occupational accidents in the field of delivery transportation by adopting the classical accident analysis model by Reason (1997). Accordingly, we will concentrate on unsafe acts by the driver, local workplace factors and, eventually, on organisational factors. In their review, Sheikhalishahi et al. (2016) have analysed several different industrial work environments in the context of human factors in maintenance. The dimension of supply chains in maintenance was not discussed in their review, but proposed as a topic for future studies. In this study, we add an important dimension of delivery transportation, in which we discuss the human factors in maintenance from the supply chain perspective by our accident-focused analyses.

\section{Methods and Materials}

Up-to-date national accident statistics are analysed to provide a better understanding of the accident risks in road transportation work. The analysis of accident statistics is supplemented with an in-depth examination of public reports from fatal occupational accidents in Finland that occurred in the road transportation sector. By this, we add an important dimension of learning from accidents to respond to the suggestions proposed by Tarakci (2016) to learn from failures in maintenance. The aim for the latter part of this analysis is to contemplate what would have been the role of maintenance in preventing such accidents. To elaborate on this further, the role of maintenance is discussed from the human factors in maintenance perspective (refer to Sheikhalishahi et al., 2016), or in other words, to provide a better understanding of the contributing factors for fatal occupational accidents by preventing similar accidents in the future.

In the occupational accident statistics part of this study, the focus is on occupational accidents that have occurred in Finland for truck drivers between 2010 and 2019. Data was collected on 20 April 2020, from the Pakki online statistics database. Pakki is administered by the Finnish Workers' Compensation Center. All occupational accidents that are compensated at some level are reported by accident insurance companies to the Pakki database. Special attention is paid to the Transportation and Storage branch under which transportation-specific accidents are coded in the Pakki system. Branch codification and a more specific codification of the accidents is based on standard industrial classification and the accident statistics classifications by the European Commission (2012).

Concerning the fatal accidents, publicly available data from the TOTTI (2020) database is analysed. TOTTI is a database administered by the Finnish Workers' Compensation Center that provides detailed descriptions of selected fatal accidents in Finland (Workers' Compensation Center, 2016). The Pakki database reports 
that 405 fatal occupational accidents have occurred in Finland from 2005 to 2018 . From these, 91 have been classified under the Transportation and Storage branch. The TOTTI Database was analysed using the search word "Driver" (In Finnish: Kuljettaja) to search all the reported 922 fatal accidents in the database. The search resulted in 36 fatal accidents involving the search term, from which 14 cases were deemed to represent the transport sector and the focus areas of this study (i.e., the accident had occurred at clients' premises or courtyards and public areas) and were thus included in the final analysis. Cases excluded were instances where the accident had occurred while driving or the driver was performing maintenance or road construction work (i.e. cases that are not directly linked to the focus areas of this study).

Fatal accident reports $(n=14)$ are analysed based on the root causes identified by the inspection teams utilizing the three categories defined by Reason (1997): unsafe acts, local workplace factors and organisational factors. Accordingly, unsafe acts include both intentional and unintentional acts; local workplace factors include both work environment and technology-related factors; whilst organisational factors relate to organisation-level practices and processes. Based on the root cause analyses, four different scenarios were created for fatal accidents in drivers' work outside the cab. The scenarios with five different risk management measures (technical improvement, better work instructions, training, supervision and other) were presented to seven OSH experts (four researchers and three specialists) with the aim of prioritizing the measures for the scenarios. The risk management measures were based on proposals that the inspection teams had proposed in reports derived from the Pakki database. Prioritization was made by placing the given measures in order from 1 to 5 , where " 1 " meant the first measure that the expert considered the most effective concerning the scenario, and " 5 " meant the least effective measure from the given options. The prioritization order was made by totalling the number scores for each measure and for each scenario. Thus, the measure that was given the lowest total score was considered to be the most efficient measure in the situation described in the scenario.

\section{Results}

The Transportation and Storage branch has had the second highest accident frequency (accidents per million working hours) behind the Construction branch for the whole inspection period when different branches were compared. The development for the accident frequency has been very modest, almost none during 2010s. In 2010, the accident frequency was 45.0 (for all compensated accidents) and clearly above the average number for all industries (30.2); yet, the accident frequency was smaller when compared to Construction (68.1). During the eight-year period from 2010 to 2018, the frequencies have decreased rather modestly to 39.3 in the Transportation and Storage branch, 60.1 in the Construction branch and 29.1 as the average across all branches.

To provide more in-depth understanding about the nature of fatal accidents in Finland, the Transportation and Storage branch statistics for 2018 in the Pakki database were examined. Altogether 7,617 occupational accidents were reported in the database and classified under the Transportation and Storage branch that year. As an indication of the predominance of the accidents outside the cab when compared to accidents while driving, only 630 (8.3\%) accidents were coded under the "driving/being on board a means of transport or handling equipment" category. In this category of specific physical activities, the categorisation is made based on the exact specific physical activity the victim was performing at the instant of the accident. To be more precise, this category includes not only driving a means of transport but also handling of equipment (mobile, motorised and non-motorised) and being a passenger on board a means of transport. Thus, it can be concluded that a vast majority (over $90 \%$ ) of the occupational accidents in the Transportation and Storage branch occur outside the cab. Concerning the work environments where the 
accidents had been categorised, there were two categories that arose from the analyses: public areas (30.7\% of the accidents) and areas used principally for storage, loading and unloading (27.4\%).

Most of the accidents were related to human movement (38.7\%), for example, the victim was moving at the instant of the accident; handling of objects (18.6\%); or carrying an object by hand (17.9\%). The most usual contact-mode of injury was horizontal or vertical impact with or against a stationary object, from which $38.1 \%$ of the accidents were categorised. In addition, sudden physical or mental stress was associated with $18.1 \%$ of the accidents, and $13.1 \%$ of the accidents were related to a victim being struck by an object in motion. Next, the accidents were examined based on their categorised deviations, or in other words, how they had been categorised based on the last event differing from the norm and leading up to the accident. Slipping, stumbling and falling were identified as the deviation factor for $34.9 \%$ of the accidents and body movement under or with physical stress for $14.7 \%$ of the accidents. The most common body parts injured were the lower extremities (31.0\%) and upper extremities (30.2\%).

All in all, the above statistical analyses indicate the need to pay more attention to the activities the truck drivers are performing outside the cabs. Accidents seem to occur at work environments that are not necessarily supervised by the transportation company. Such environments include customers' premises and public areas where the driver is performing several different activities in addition to their delivery tasks. Consequently, a closer look at the accident descriptions for fatal accidents in the Transportation and Storage branch was conducted. Altogether, 14 fatal accidents were included in this phase. Descriptions, identified root causes and preventive solutions suggested by the inspection teams who had written the reports are summarized in Appendix 1.

All the accidents described in Appendix 1 occurred while performing work tasks outside the cab in work environments that are not supervised or managed by the transportation company. The root causes for the accidents - as identified by the inspection teams - were multifaceted. However, some common characteristics stand out in our analysis. Primarily the accidents seem to be caused by a combination of different root causes. Based on our analysis, the root causes identified by the inspection teams included unintentional unsafe acts, intentional violation of safety rules (unsafe acts); malfunctioning tools and technological equipment and unsafe work environments (local workplace factors); and unproper risk analyses and management practices (organisational factors), as presented in Table 1.

\section{TABLE 1 ABOUT HERE}

In the cases reported as unsafe acts (see Table 1), the inspection teams were not always able to detect whether the victim had purposely conducted an unsafe act resulting in the accident, or if the unsafe act was unintentional. As Table 1 shows, the role of maintenance can be interpreted manifold when the accidents are examined from the maintenance perspective. Firstly, the cases included accidents where the driver was forced to perform certain maintenance and cleaning tasks on-road or at the customers' premises and in public areas. Often, the driver had performed the maintenance task alone with no supervision or without another co-worker present, thus making it impossible to understand whether the unsafe act leading up to the accident had been intentional or unintentional. To make such actions safer, it is evident that the instructions and procedures for such maintenance actions must be up to date. Collaboration between the transportation company and the client is necessary in such cases to prevent the driver from making any unintentional and unsafe choices because of too little information about the characteristics or conditions of the workplace. In addition, from the preventative maintenance perspective, it is evident that the equipment used for maintenance on road are safe. In some cases, the accident was favoured by unsafe equipment that was used by the driver. Empirical material in this study as such does not allow interpreting the owner of the equipment at all cases. However, there were cases in instances where the equipment used was attached to the truck. In such cases, the maintenance of the equipment lies on the shoulders of 
the transportation company. For instance, in some cases, the safeguards had been removed or were totally missing. Empirical material of this study does not identify whether this was due to the drivers' own decisions to not use or to neglect the utilization of such safeguards. However, based on risk management premises, the total responsibility still lies on the shoulders of the employer. A question that was left answered in many cases was how the maintenance of such equipment had been verified. In such cases, preventive maintenance, proper documentation and safety supervision would be beneficial. All in all, as a preventive maintenance action, the possibility of violations or misuse of technical safeguards and mechanical locks should be made impossible, and better guidance should be provided to facilitate better understanding and reasoning for such safety solutions.

In all 14 cases, the work environment was at some level identified as the root cause for the accident. In many cases, the surface for the truck was inclined, making it possible for the vehicle to move unintentionally if the hand break was not used or was misfunctioning. In such cases, a question that was often left unanswered relates to both workplace design and organisational factors: how was the risk management process performed and by who, and how were the results of the process communicated to the driver? If the risk management process had been performed adequately, another question related to the practical arrangements at the workplace was often left unanswered: if the risks had been identified, how had they been managed? In some cases, proper risk management processes and up-to-date workplace maintenance would potentially remove or minimise the risks, which in turn, if communicated properly to the driver, would have prevented the potential for misuse or a misunderstanding.

As shown in the accident descriptions (Appendix 1) and root cause analyses (Table 1) of the 14 accidents included in this analysis, each accident included several root causes, instead of only a single root cause. As discussed earlier, unsafe acts may include both intentional and unintentional acts by the driver. There were signs of intentional violation of safety rules in four cases, three of which were related to the misuse of personal protective equipment, and the fourth to the work environment in which the driver chose to work. Based on the above root causes, analyses of four short accident scenarios (a-d, Table 2 ) were created to illustrate typical circumstances for fatal accidents of truck drivers during work outside the cab. Accident scenarios were presented to OSH experts to prioritize different risk management measures.

\section{TABLE 2 ABOUT HERE}

The prioritization results are presented in Table 3. Accordingly, technical solutions are considered to be the most efficient for scenarios that contain unintentional unsafe acts. That is the case both when the driver is working at unsafe work environments (all 7 experts prioritised technical solutions as the most efficient measure) and when working with malfunctioning tools and technologies (6 prioritizations for the most efficient measure). Concerning the scenarios where a violation of safety rules was illustrated, the prioritization for the measures was clearly not as distinct as for the unintentional unsafe acts. Better work instructions were generally considered to be the most efficient measure; however, the individual range of scores varied from 1 to 4 showing the complexity of affecting individual's willingness to act safely. The results of the prioritization are only indicative due to the low number of respondents. However, the results clearly show the complexity of the measures needed for preventing occupational accidents outside the cab.

\section{TABLE 3 ABOUT HERE}

\section{Discussion and Conclusions}

The findings of this study draw a brutally realistic picture of the delivery truck drivers' work outside the cab. Drivers' constantly perform work tasks that contain risks for hazards. Fluent and safe deliveries require resilience at both the individual and organisational levels. In practice, resilient individuals and organisations, as defined by Hollnagel (2011), have the ability to respond to different events, monitor 
ongoing developments, anticipate future threats and opportunities, and learn from past failures and successes. In the delivery transportation context, these abilities reflect the drivers' skills and abilities to adapt to continuously changing circumstances and resolve practical problems, such as maintenance issues on-site. Employers' opportunities to supervise drivers' work are very limited, highlighting the need for efficient learning from earlier failures and proactive risk management actions. In referring to Kleiner et al. (2015), it can be questioned how such complex human-system entities that contain interdependent dimensions of effectiveness, efficiency and safety are in practice managed. As further highlighted by Kleiner et al. (2015), successful long-term system performance is likely not achieved when any of these dimensions is neglected in management actions.

The global literature concerning transportation is consistent in reporting the complexity of this challenging work and the variety of different OSH hazards truck drivers constantly face. When referring to the theory of a balanced organisation (Smith and Carayon, 2000), it is easy to conclude that the balance is not achieved at either the individual or at the organisational level. Accident statistics from Finland show - similarly to the global literature - that rather little positive development has been achieved during the 2000s. That is somewhat surprising, considering the broad technologic development and trend of general development in the area of occupational safety that, for example, Hoffmann et al. (2017) have described in their review. Even though scientific literature and practices in general show that technology is rapidly replacing human work in many ways, it does not provide insight into whether humans would be replaced by a machines in the transportation sector in the near future like Freeman ( 2017) has concluded. For instance, given the fact that mail order for goods are generally on the rise by private citizens, it would be easy to conclude that the delivery transportation and drivers' work outside the cab at various clients' environments will not decrease.

Corporate social responsibility brings an additional dimension to this discussion on safety outside the cab. As brought out by different authors, like Zink and Fischer (2013), OSH should be acknowledged thorough the value chains, and stakeholder management should be multifaceted to include all relevant actors' affecting and being affected by this safety. It is easy to agree with the findings of Bolis et al. (2014) and conclude - based on the findings of this study - that the social context and human work is in many ways neglected in current stakeholder management processes in delivery transportation, and the role of corporate social responsibility is blurred to the actors in the field of road transportation.

\section{Managerial implications}

It is pertinent to pay more attention to human factors in maintenance in road transport. The spectrum of areas to be maintained is wide and not restricted to transportation companies' premises and trucks, truck bodies and cargo spaces. Instead, the results of this study indicate that more focus should be paid on work environments during the delivery operations (clients' premises and courtyards and public areas). The role of maintenance is manifold in this. Naturally, truck-specific maintenance practices should be developed, and more attention should be paid to preventive actions that would decrease the need for unplanned maintenance actions during the delivery operations. Noticing the fact that delivery truck companies are often small by their number of employees or they might even be self-employed entrepreneurs (European Agency for Safety and Health at Work, 2010), a specific challenge of resourcing truck maintenance in practice should be acknowledged.

The challenge related to the maintenance of clients' premises and courtyards and public areas is much more complex in nature. The responsibilities are often not described adequately, or their supervision is left with little attention. Additionally, selecting the most suitable risk management measures is not a straightforward process, as our study shows. Instead, a combination of measures is often needed. A common practice of outsourcing maintenance, cleaning and janitorial services - especially in industrial contexts (see Milch and Laumann, 2016) - brings an extra dimension for risk management in this multi- 
stakeholder entity that can be considered a shared workplace. If the premises where clients' goods are delivered are owned by a third party, and the maintenance services are bought as an outsourced service from another party, the role of deliveries as a daily - but still not constant - service might be blurry to all other stakeholders. This might in turn complicate the understanding of the needs of different maintenance actions. More attention should be paid to logistics development from a social network perspective as proposed by Barata et al. (2018). In addition, possible differences on occupational accidents between short haul- and long haul-operations should be considered a topic for future research.

\section{Limitations}

The Pakki database does not differentiate whether the injured driver was a short- or long-haul driver. However, as a vast majority of the accidents occurred outside the cab, it is reasonable to use these somewhat inadequate statistics for the study purposes - as a basis for this study focusing on maintenance at work tasks outside the cab. The TOTTI Database does not contain all fatal occupational accidents in Finland. The selection of an accident's inclusion in the database is made by a specialist group represented by safety authorities and an insurance business. Thus, it is reasonable to assume that the database includes such accidents that are relevant to the branch. In addition, the Pakki database includes only accidents that have occurred for wage-earners (employed people), and occupational accidents by self-employed entrepreneurs are not included in the database. The Pakki and TOTTI analyses were made solely by the author. The data selection process has been described by good scientific practice, which decreases potential for subjective biases in the analysis phase. In addition, the number of OSH experts prioritizing the risk management measures was limited, making further statistical analyses not reasonable. Thus, the prioritization of the measures should be considered only as indicative. 


\section{References}

Anderson, N., Smith, C.K. and Byrd, J.L. (2017), "Work-related injury factors and safety climate perception in truck drivers", American Journal of Industrial Medicine, Vol. 60 No. 8, pp. 711-723.

Anumba, C.J., Siemieniuch, C.E. and Sinclair, M.A. (2000), "Supply chain implications of concurrent engineering", International Journal of Physical Distribution \& Logistics Management, Vol. 30 No. 7, pp. 566597.

Apostolopoulos, Y., Lemke, M. and Sönmez, S. (2014), "Risks endemic to long-haul trucking in North America: strategies to protect and promote driver well-being", New Solutions, Vol. 24 No. 1, pp. 57-81.

Barata, J., da Cunha, P.R. and Stal, J. (2018), "Mobile supply chain management in the Industry 4.0 era. An annotated bibliography and guide for future research", Journal of Enterprise Information Management, Vol. 31 No. 1, pp. 173-193.

Bedinger, M., Walker, G.H., Piecyk, M. and Greening, P. (2016), "21st century trucking: a trajectory for ergonomics and road freight", Applied Ergonomics, Vol. 53 Part B, pp. 343-356.

Bolis, I., Brunoro, C.M. and Sznelwar, L.I. (2014), "Mapping the relationships between work and sustainability and the opportunities for ergonomic action", Applied Ergonomics, Vol. 45 No. 4, pp. 12251239.

Cantor, D.E. (2008), "Workplace safety in the supply chain: a review of the literature and call for research", International Journal of Logistics Management, Vol. 19 No. 1, pp. 65-83.

Carayon, P. and Smith, M.J. (2000), "Work organization and ergonomics", Applied Ergonomics, Vol. 31 No. 6, pp. 649-662.

Chandler, M.D., Bunn, T.L. and Slavova, S. (2017), “Narrative and quantitative analyses of workers' compensation-covered injuries in short-haul vs long-haul trucking", International Journal of Injury Control and Safety Promotion, Vol. 24 No. 1, pp. 120-130.

Custódio, A.L. and Oliveira, R.C. (2006), "Redesigning distribution operations: a case study on integrating inventory management and vehicle routes design", International Journal of Logistics Research and Applications, Vol. 9 No. 2, pp. 169-187.

de Langen, P.W. and Chouly, A. (2009), "Strategies of terminal operating companies in changing environments", International Journal of Logistics Research and Applications, Vol. 12 No. 6, pp. 423-434.

Douglas, M.A. and Swartz, S.M. (2017), "Knights of the road: safety, ethics, and the professional truck driver", Journal of Business Ethics, Vol. 142 No. 3, pp. 567-588.

Douglas, M.A., Swartz, S.M., Richey, G. and Roberts, M.D. (2019), "Risky business: investigating influences on large truck drivers' safety attitudes and intentions", Journal of Safety Research, Vol. 70, pp. 1-11.

Dul, J., Bruder, R., Buckle, P., Carayon, P., Falzon, P., Marras, W.S., Wilson, J.R. and van der Doelen, B. (2012), "A strategy for human factors/ergonomics: developing the discipline and profession", Ergonomics, Vol. 55 No. 4, pp. 377-395.

European Agency for Safety and Health at Work. (2010), "A review of accidents and injuries to road transport drivers", available at: https://osha.europa.eu/en/publications/review-accidents-and-injuriesroad-transport-drivers (accessed 10th Aug 2020).

European Commission. (2001), "European Statistics on Accidents at Work", available at: https://ec.europa.eu/eurostat/documents/3859598/5926181/KS-RA-12-102-EN.PDF/56cd35ba-1e8a-4af39f9a-b3c47611ff1c (accessed 10th Aug 2020).

Fathallah, F.A., Grönqvist, R. and Cotnam, J.P. (2000), "Estimated slip potential on icy surfaces during various methods of exiting commercial tractors, trailers and trucks", Safety Science, Vol. 36 No. 2, pp. 6981. 
Fischer, K., and Zink, K.J. (2012), "Defining elements of sustainable work systems - a system-oriented approach", Work, Vol. 41 No. Suppl. 1, pp. 3900-3905.

Freeman, D.H. (2017), "Self-driving trucks", MIT Technology Review, Vol. 120 No. 2, pp. 62-71.

Friswell, R. and Williamson, A. (2010), "Work characteristics associated with injury among light/short-haul transport drivers", Accident Analysis \& Prevention, Vol. 42 No. 6, pp. 2068-2074.

García-Arca, J., Prado-Prado, J.C. and Fernández-González, A.J. (2018), "Integrating KPIs for improving efficiency in road transport", International Journal of Physical Distribution \& Logistics Management, Vol. 48 No. 9, pp. 931-951.

Hofmann, D.A., Burke, M.J. and Zohar, D. (2017), "100 years of occupational safety research: from basic protections and work analysis to a multilevel view of workplace safety and risk", Journal of Applied Psychology, Vol. 102 No. 3, pp. 375-388.

Hollnagel, E. (2011), "Prologue: the scope of resilience engineering”, Hollnagel, E., Pariès, J., Woods, D.D. and Wreathall, J. (Eds.), Resilience engineering in practice. A Guidebook, Ashgate Publishing Limited, Farnham, UK, pp. XXIX-XXXIX.

Kleiner, B.M., Hettinger, L.J., DeJoy, D.M., Huang, Y-H. and Love, P.E.D. (2015), "Sociotechnical attributes of safe and unsafe work systems", Ergonomics, Vol. 58 No. 4, pp. 635-649.

McClay, R.E. (2008), "Truck falls: examining the nature of the problem", Professional Safety, Vol. 53 No. 5, pp. 26-35.

Milch, V. and Laumann, K. (2016), "Interorganizational complexity and organizational accident risk: a literature review", Safety Science, Vol. 82, pp. 9-17.

Olson, R., Hahn, D.I. and Buckert, A. (2009), "Predictors of severe trunk postures among short-haul truck drivers during non-driving tasks: an exploratory investigation involving video-assessment and driver behavioural self-monitoring", Ergonomics, Vol. 52 No. 6, pp. 707-702.

Parida, A., Kumar, U., Galar, D. and Stenström, C. (2015), "Performance measurement and management for maintenance: a literature review", Journal of Quality in Maintenance Engineering, Vol. 21 No. 1, pp. 2-33.

Reason, J. (1997), Managing the risks of organisational accidents, Ashgate Publishing Limited, Aldershot, UK.

Reiman, A., Forsman, M., Målqvist, I., Parmsund, M. and Lindahl Norberg, A. (2018). "Risk factors contributing to truck drivers' non-driving occupational accidents", International Journal of Physical Distribution and Logistics Management, Vol. 48 No. 2, pp. 183-199.

Reiman, A., Pekkala, J., Väyrynen, S., Putkonen, A. and Forsman, M. (2014), “Participatory video-assisted evaluation of truck drivers' work outside cab: deliveries in two types of transport", International Journal of Occupational Safety and Ergonomics, Vol. 20 No. 3, pp. 477-489.

Reiman, A. and Väyrynen, S. (2018), "Holistic well-being and sustainable organizations - a review and propositions", International Journal of Sustainable Engineering, Vol. 11 No. 5, pp. 321-329.

Sheikhalishahi, M., Pintelon, L. and Azadeh, A. (2016), "Human factors in maintenance: a review", Journal of Quality in Maintenance Engineering, Vol. 22 No. 3, pp. 218-237.

Shibuya, H., Cleal, B. and Kines, P. (2010), "Hazard scenarios of truck drivers' occupational accidents on and around trucks during loading and unloading", Accident Analysis and Prevention, Vol. 42 No. 1, pp. 19-29.

Smith, M., and Sainfort, P.C. (1989), "A balance theory of job design for stress reduction", International Journal of Industrial Ergonomics, Vol. 4 No. 1, pp. 67-69.

Statistics Database Pakki (2020), "Tilastosovellus Pakki [Statistics database Pakki]", Available at: www.tvk.fi/pakki (accessed 20 April 2020). 
Statistics Database TOTTI (2020), "TOT-tutkinta [Inspection database for fatal occupational accidents]", Available at: http://totti.tvk.fi (accessed 20 April 2020).

Tarakci, H. (2016), "Two types of learning effects on maintenance activities", International Journal of Production Research, Vol. 54 No. 6, pp. 1721-1734.

van der Beek, A.J. (2012), "World at work: truck drivers", Occupational \& Environmental Medicine, Vol. 69 No. 4, pp. 291-295.

Workers' Compensation Center. (2016), "TOT-tutkinnan käsikirja" [In English: Handbook for inspecting fatal occupational accidents], Available at:

https://www.tvk.fi/templates/vinha/services/download.aspx?fid=353930\&hash=cfbdef29a99352bf8ce550 3bf414632b7ea4c8a85f9d84a6f86fcea1369a1093 (accessed 10th Aug 2020).

Zink, K.J. and Fischer, K. (2013), "Do we need sustainability as a new approach in human factors and ergonomics?", Ergonomics, Vol. 56 No. 3, pp. 348-356. 